\title{
Effects of the sperm DNA fragmentation index on the clinical and neonatal outcomes of intracytoplasmic sperm injection cycles
}

\author{
Linjun Chen ${ }^{*}$ (D) Junshun Fang, Weihua Jiang, Jie Wang and Dong Li
}

\begin{abstract}
Background: Most studies have mainly focused on the effects of the sperm DNA fragmentation index (DFI) on fertilization, embryonic developmental potential and aneuploidy, pregnancy and abortion rates after in vitro fertilization (IVF)/intracytoplasmic sperm injection (ICSI) and have remained controversial. However, few studies have reported the effects of sperm DFI on neonatal outcomes, including stillbirths, neonatal deaths, sex, gestational age, prematurity, birthweight, low birth weight (LBW) and birth defects in newborns. Our objective was to evaluate the effects of sperm DFI on the clinical and neonatal outcomes of ICSI cycles.

Methods: This retrospective study analysed a total of 2067 oocyte retrieval, 1139 transfer and 713 delivery cycles from conventional ICSI cycles, including 301, 469, and 214 live-born infants in groups segregated according to sperm DFI as the $<15 \%, 15-30 \%$ and $>30 \%$ groups, respectively. The clinical and neonatal outcomes were compared among the three groups.

Results: Sperm DFI did not significantly affect the rates of fertilization, clinical pregnancy, miscarriage or ongoing pregnancy. Sperm DFI did not increase the risk of stillbirths or neonatal deaths. The rates of stillbirths and neonatal deaths were not significantly different among the three groups. The sex, gestational age, prematurity, birthweight and LBW of newborns in the three groups were not significantly affected by sperm DFI. Moreover, sperm DFI did not increase the number of birth defects in children.
\end{abstract}

Conclusions: Sperm DFI did not affect the clinical or neonatal outcomes of ICSI cycles.

Keywords: Sperm, DNA fragmentation index, Neonatal outcomes, Intracytoplasmic sperm injection, Birth defects

\section{Background}

The integrity of sperm DNA is important for embryonic development and pregnancy. Sperm DNA damage is even frequently found in normozoospermic men [1]. Sakkas et al. [2] reported six main factors (apoptosis, DNA strand breaks, reactive oxygen species (ROS),

\footnotetext{
* Correspondence: chenlinjun158@163.com

Reproductive Medical Center, Nanjing Drum Tower Hospital, The Affiliated Hospital of Nanjing University Medical School, ZhongshanRoad 321\#, Nanjing, 210008, People's Republic of China
}

endogenous caspases and endonucleases, radio- and chemotherapy, and environmental toxicants) that induced sperm DNA damage. The extent of sperm DNA damage is measured by the sperm DNA fragmentation index (DFI).

Santi et al. [3] reported that sperm DFI had a higher accuracy than conventional sperm parameters for sperm functional analysis. Alvarez Sedó et al. [4] reported that sperm DFI was negatively associated with the rates of blastulation and pregnancy in intracytoplasmic sperm

(c) The Author(s). 2020 Open Access This article is licensed under a Creative Commons Attribution 4.0 International License, which permits use, sharing, adaptation, distribution and reproduction in any medium or format, as long as you give appropriate credit to the original author(s) and the source, provide a link to the Creative Commons licence, and indicate if changes were made. The images or other third party material in this article are included in the article's Creative Commons licence, unless indicated otherwise in a credit line to the material. If material is not included in the article's Creative Commons licence and your intended use is not permitted by statutory regulation or exceeds the permitted use, you will need to obtain permission directly from the copyright holder. To view a copy of this licence, visit http://creativecommons.org/licenses/by/4.0/ The Creative Commons Public Domain Dedication waiver (http://creativecommons.org/publicdomain/zero/1.0/) applies to the data made available in this article, unless otherwise stated in a credit line to the data. 
injection (ICSI) patients with donated oocytes. Zheng et al. [5] found that sperm DFI had a negative effect on day 3 embryo quality and the rates of blastocyst formation, implantation and pregnancy in patients undergoing in vitro fertilization (IVF). Two meta-analyses showed that high sperm DFI had lower good-quality embryo and clinical pregnancy rates and increased miscarriage rates after IVF/ICSI than did low sperm DFI [6, 7]. However, Sun et al. [8] reported that sperm DFI did not predict embryo quality or pregnancy rate after IVF/ICSI. Sperm DFI was also not associated with blastocyst aneuploidy, morphological grading or clinical outcomes after preimplantation genetic screening [9]. Another two meta-analyses concluded that sperm DFI did not predict IVF/ICSI outcomes $[10,11]$. Antonouli et al. [12] reported that sperm DFI did not significantly affect embryonic development or pregnancy rate in ICSI patients with donated oocytes. From the literatures published above, the effect of sperm DFI on embryonic development, implantation and pregnancy remained controversial after IVF/ICSI.

At present, most studies have mainly focused on the effect of sperm DFI on fertilization, embryonic developmental potential and aneuploidy, pregnancy and abortion rates. However, few studies have reported the effect of sperm DFI on neonatal outcomes, including stillbirths, neonatal deaths, sex, gestational age, prematurity, birthweight, low birth weight (LBW) and birth defects in newborns. In addition to the clinical outcomes, our retrospective study compared the effects of different sperm DFIs on neonatal outcomes in ICSI cycles.

\section{Methods}

\section{Patients}

All patients signed informed consent forms for ICSI and follow-up from August 2015 to December 2017 before participating in this retrospective study. All male patients were submitted to the same methods to measure sperm DFI in a sperm chromatin structure assay (SCSA) performed 1-2 months prior to oocyte retrieval. DFI values were used to categorize the subjects into three groups: < 15\%, 15-30\% and $>30 \%$. Cycles performed in patients with normal chromosomes, who did not receive antioxidant therapy prior to their IVF procedures and underwent day 3 embryo transfer were included in this study. Cycles from day 2 embryo and day 5 blastocyst transfer were excluded from this study. A total of 2067 oocyte retrieval, 1139 transfer and 713 delivery cycles, including 301, 469, and 214 live-born infants from < $15 \%, 15-30 \%$ and $>30 \%$ groups, respectively, were studied in this retrospective study.

\section{Definitions}

The published literature [13] was used to define clinical pregnancy, miscarriage, gestational age, prematurity, LBW, live births and stillbirths.

\section{Follow-up}

Data on the clinical outcomes and neonatal outcomes, including clinical pregnancy, miscarriage, the date of birth, sex, live-birth or not, birthweight and birth defects in newborns, were gathered through phone calls and electronic database registration.

\section{Statistics}

SPSS 22.0 software was used for all data analyses. An independent samples Kruskal-Wallis test was used to compare means among the three groups. The $\chi^{2}$ test was used to compare rates among the three groups. $P<0.05$ indicated statistical significance.

\section{Results}

Duration of infertility and male BMI were not significantly different among the three groups. Female BMI in high sperm DFI group (15-30\%) was significantly lower compared with that in low sperm DFI group $(<15 \%)$, while the distribution of primary infertility and thickness of the endometrium in the $15-30 \%$ group were significantly higher compared with that in the DFI $<15 \%$ group. Female age and male age were significantly different among the three groups, while sperm DFI significantly increased as female age and male age increased (Table 1), which was consistent with the reported literatures $[12,14]$.

The clinical outcomes, including average number of transferred and frozen embryos, the rates of fertilization, biochemical pregnancy, clinical pregnancy, miscarriage and ongoing pregnancy were not significantly different among the three groups (Table 2).

There was one stillbirth in each of the DFI $<15 \%$ and $15-30 \%$ groups, and there was no stillbirth in the DFI >

$30 \%$ group. There were no significant differences in stillbirths among the three groups. There was one neonatal death in the DFI $<15 \%$ group, there were four neonatal deaths in the 15-30\% group, and there was one neonatal death in the DFI > 30\% group. There was no significant difference in the rate of neonatal deaths among the three groups (Table 3).

There were no significant differences in the sex or gestational age of newborns among the three groups. Gestational age was significantly larger for twins in the DFI $<15 \%$ and $>30 \%$ groups than for those in the $15-$ $30 \%$ group. There was no significant difference in prematurity among the three groups. The prematurity rate of twins in the DFI $<15 \%$ group was significantly lower than that in the $15-30 \%$ group. There were also no significant differences in birthweight or LBW in newborns among the three groups (Table 4).

For birth defects, there was one birth defect (cleft lip) in the DFI $<15 \%$ group, and there were four birth defects (abnormality of the external auditory canal (1), cleft 
Table 1 Patient characteristics according to sperm DFI

\begin{tabular}{|c|c|c|c|c|}
\hline & $<15 \%$ & $15-30 \%$ & $>30 \%$ & $p$-Value \\
\hline Female age (years) & $30.9 \pm 5.4^{\mathrm{a}}$ & $30.8 \pm 5.3^{b}$ & $32.0 \pm 5.7^{a, b}$ & $<0.001$ \\
\hline Female BMI $\left(\mathrm{kg} / \mathrm{m}^{2}\right)$ & $22.7 \pm 3.1^{\mathrm{a}}$ & $22.4 \pm 3.1^{\mathrm{a}}$ & $22.7 \pm 3.1$ & 0.033 \\
\hline \multicolumn{5}{|l|}{ Pattern of infertility } \\
\hline Primary & $408(59.0)^{\mathrm{a}, \mathrm{c}}$ & $623(65.4)^{\mathrm{a}}$ & $260(61.6)$ & 0.027 \\
\hline Secondary & $284(41.0)$ & $330(34.6)$ & $162(38.4)$ & - \\
\hline Duration of infertility (years) & $4.2 \pm 3.3$ & $4.1 \pm 3.3$ & $4.6 \pm 3.6$ & 0.054 \\
\hline Thickness of endometrium (mm) & $10.6 \pm 2.9^{\mathrm{a}}$ & $11.1 \pm 3.0^{\mathrm{a}}$ & $10.8 \pm 3.0$ & 0.002 \\
\hline Male age (years) & $32.3 \pm 5.8^{\mathrm{a}}$ & $32.7 \pm 6.3^{d}$ & $34.1 \pm 7.4^{\mathrm{a}, \mathrm{d}}$ & 0.001 \\
\hline Male BMI $\left(\mathrm{kg} / \mathrm{m}^{2}\right)$ & $24.9 \pm 3.9$ & $24.8 \pm 4.0$ & $24.5 \pm 3.9$ & 0.194 \\
\hline DFI (\%) & $9.8 \pm 3.3^{b}$ & $22.2 \pm 4.3^{b}$ & $39.8 \pm 9.9^{b}$ & $<0.001$ \\
\hline
\end{tabular}

soft palate (1), congenital heart disease (1), and joint deformity of the left index and middle fingers (1)) in the $15-30 \%$ group and two birth defects (Down syndrome (1) and an extra finger near the right thumb (1)) in the DFI $>30 \%$ group. There were no significant differences in birth defects among the three groups (Table 5).

\section{Discussion}

This retrospective study showed that sperm DFI did not significantly affect the fertilization, clinical pregnancy, miscarriage, ongoing pregnancy, stillbirths, neonatal deaths, prematurity or LBW rates, gestational age or birthweight of newborns among the different groups.

Sun et al. reported that there were no significant difference in the rates of fertilization, clinical pregnancy or ongoing pregnancy between high $(\geq 30 \%)$ and low (< $30 \%)$ sperm DFI groups from IVF or ICSI cycles [8]. A prospective cohort study showed that sperm DFI was not associated with the fertilization or ongoing pregnancy rate after ICSI cycles [15]. Consistent with the studies mentioned above, our retrospective study found that sperm DFI did not adversely affect the rates of fertilization, clinical pregnancy or ongoing pregnancy in ICSI cycles (Table 2). Zhu et al. reported that the increased sperm DFI was associated with unexplained recurrent pregnancy loss [16]. Yang et al. found that the early abortion rate in intrauterine insemination (IUI) cycles was significantly increased as sperm DFI increased, while there was no significant difference in ICSI cycles [14]. The present study obtained similar results, namely, that the miscarriage rate was not significantly different among different sperm DFI groups (Table 2). This may be related to the fact that spermatozoa showing normal morphology with less DNA damage are used for ICSI [17-19] and that the most viable embryos are chosen for subsequent transfer.

Simon et al. reported that infertile couples with high sperm DFI had a much lower live-birth rate after conventional IVF than infertile couples with a low sperm DFI, while there was no significant difference in livebirth rate in couples undergoing ICSI cycles [20]. A systematic review and meta-analysis also showed that high

Table 2 Clinical outcomes of transfer cycles according to sperm DFI

\begin{tabular}{|c|c|c|c|c|}
\hline & $<15 \%$ & $15-30 \%$ & $>30 \%$ & $p$-Value \\
\hline Number of oocyte retrieval cycles & 692 & 953 & 422 & - \\
\hline Average number of MII oocytes & $7.6 \pm 4.6^{a}$ & $8.2 \pm 4.7^{\mathrm{a}}$ & $8.2 \pm 4.9$ & 0.009 \\
\hline Number of fertilized oocytes & $4209(80.3)^{b}$ & $6276(79.9)$ & $2754(79.9)$ & 0.846 \\
\hline Number of transfer cycles & $344(49.7)^{\mathrm{a}, \mathrm{c}}$ & $558(58.6)^{c}$ & $237(56.2)^{\mathrm{a}}$ & 0.002 \\
\hline Average number of transferred embryos & $1.9 \pm 0.4$ & $1.9 \pm 0.3$ & $1.9 \pm 0.3$ & 0.621 \\
\hline Average number of frozen embryos & $2.33 \pm 2.30$ & $2.49 \pm 2.36$ & $2.43 \pm 2.31$ & 0.276 \\
\hline Number of biochemical pregnancy & $247(71.8)$ & $403(72.2)$ & $175(73.8)$ & 0.854 \\
\hline Number of clinical pregnancy & $241(70.1)$ & $386(69.2)$ & $168(70.9)$ & 0.884 \\
\hline Number of miscarriage & $23(9.5)$ & $32(8.3)$ & $20(11.9)$ & 0.408 \\
\hline Number of termination of pregnancy & $2(0.8)$ & $5(1.3)$ & $0(0.0)$ & 0.423 \\
\hline Number of ongoing pregnancy & $216(89.6)$ & $349(90.4)$ & $148(88.1)$ & 0.711 \\
\hline
\end{tabular}

${ }^{\mathrm{a}} P<0.05,{ }^{\mathrm{C}} P<0.001,{ }^{\mathrm{b}}$ values in parenthesis are expressed in percentage 
Table 3 Live births, stillbirths, and neonatal deaths according to sperm DFI

\begin{tabular}{|c|c|c|c|c|}
\hline & $<15 \%$ & $15-30 \%$ & $>30 \%$ & $p$-Value \\
\hline Number of delivery cycles & 216 & 349 & 148 & - \\
\hline Singletons & $130(60.2)^{\mathrm{a}}$ & $228(65.3)^{b}$ & $82(55.4)^{b}$ & 0.098 \\
\hline Twins & $86(39.8)$ & $121(34.7)$ & $66(44.6)$ & - \\
\hline Number of live births & 301 & 469 & 214 & - \\
\hline Singletons & 130 & 228 & 82 & - \\
\hline Twins & 171 & 241 & 132 & - \\
\hline Number of neonatal deaths & $1(0.3)$ & $4(0.9)$ & $1(0.5)$ & 0.867 \\
\hline Singletons & $1(0.8)$ & $2(0.9)$ & 0 & 1.000 \\
\hline Twins & 0 & $2(0.8)$ & $1(0.8)$ & 0.611 \\
\hline Number of stillbirths & $1(0.3)$ & $1(0.2)$ & 0 & 1.000 \\
\hline Singletons & 0 & 0 & 0 & - \\
\hline Twins & $1(0.6)$ & $1(0.4)$ & 0 & 1.000 \\
\hline
\end{tabular}

${ }^{a}$ values in parenthesis are expressed in percentage

${ }^{\mathrm{b}} \mathrm{P}<0.05$

sperm DFI significantly decreased the live-birth rate from couples undergoing IVF cycles but not from couples undergoing ICSI cycles [21]. This may be related to the following two main reasons [22]. One reason was that female patients undergoing ICSI cycles were younger than those undergoing IVF cycles, and the oocytes had a better ability to repair DNA damage from high DFI spermatozoa. Another reason was that high DFI spermatozoa can produce ROS and expose the oocytes to oxidative assault during sperm-oocyte incubation in IVF cycles, while ICSI did not involve this process.
Esteves et al. [23] recommended that live birth must be the most important indicator in the study of sperm DFI. In the present study, we obtained a similar result where high sperm DFI did not increase the risk of stillbirths or neonatal deaths in patients undergoing ICSI cycles (Table 3).

It has been reported that the incidences of prematurity and LBW in newborns are significantly higher after IVF/ ICSI than for natural conception [24, 25]. Seggers et al. showed that subfertility-related factors rather than the IVF treatment itself compromised perinatal outcomes

Table 4 Neonatal outcomes of live births according to sperm DFI

\begin{tabular}{|c|c|c|c|c|}
\hline & $<15 \%$ & $15-30 \%$ & $>30 \%$ & $p$-Value \\
\hline Number of live births & 301 & 469 & 214 & - \\
\hline Boys & $139(46.2)^{\mathrm{a}}$ & $219(46.7)$ & $93(43.5)$ & 0.731 \\
\hline Girls & $162(53.8)$ & $250(53.3)$ & $121(56.5)$ & - \\
\hline Gestational age (weeks) & $38.0 \pm 2.2$ & $38.1 \pm 2.4$ & $38.0 \pm 2.1$ & 0.461 \\
\hline Singletons & $39.0 \pm 1.9$ & $39.1 \pm 1.6$ & $39.0 \pm 1.3$ & 0.282 \\
\hline Twins & $36.7 \pm 1.9^{\mathrm{b}}$ & $36.1 \pm 2.4^{b, c}$ & $36.7 \pm 2.2^{c}$ & 0.043 \\
\hline Prematurity (< 37 weeks) & $78(25.9)$ & $143(30.5)$ & $60(28.0)$ & 0.395 \\
\hline Singletons & $10(7.7)$ & $23(10.1)$ & $4(4.9)$ & 0.369 \\
\hline Twins & $68(39.8)^{d}$ & $120(49.8)^{d}$ & $56(42.4)$ & 0.107 \\
\hline Birthweight (grams) & $2842.2 \pm 661.4$ & $2876.4 \pm 665.0$ & $2820.9 \pm 584.5$ & 0.411 \\
\hline Singletons & $3305.2 \pm 562.5$ & $3311.4 \pm 534.3$ & $3297.9 \pm 468.6$ & 0.826 \\
\hline Twins & $2490.3 \pm 493.4$ & $2463.1 \pm 490.6$ & $2528.3 \pm 438.0$ & 0.613 \\
\hline LBW $(<2500 \mathrm{~g})$ & $73(24.3)$ & $115(24.6)$ & $62(29.1)$ & 0.386 \\
\hline Singletons & $9(6.9)$ & $10(4.4)$ & $4(4.9)^{\mathrm{e}}$ & 0.575 \\
\hline Twins & $64(37.4)$ & $105(43.8)^{\mathrm{e}}$ & $58(43.9)$ & 0.380 \\
\hline
\end{tabular}

${ }^{a}$ value in parenthesis are expressed in percentage

$b, c, d p<0.05$

$\mathrm{e}_{\text {an infant with unknown birthweight }}$ 
Table 5 Birth defects in live-born children according to sperm DFI

\begin{tabular}{|c|c|c|c|c|}
\hline & $\begin{array}{l}< \\
15 \% \\
\end{array}$ & $15-30 \%$ & $>30 \%$ & $\begin{array}{l}p \text { - } \\
\text { Value }\end{array}$ \\
\hline \multirow[t]{2}{*}{$\begin{array}{l}\text { Number of } \\
\text { birth defects }\end{array}$} & $\begin{array}{l}1 \\
(0.3)^{\mathrm{a}}\end{array}$ & $4(0.9)$ & $2(0.9)$ & 0.693 \\
\hline & $\begin{array}{l}\text { Cleft } \\
\operatorname{lip}(1)\end{array}$ & $\begin{array}{l}\text { Abnormality of the external auditory canal ( } 1) \text {, Cleft soft palate (1), Congenital } \\
\text { heart disease (1), Joint deformity of the left index and middle fingers ( } 1 \text { ) }\end{array}$ & $\begin{array}{l}\text { Down Syndrome (1), An extra } \\
\text { finger near the right thumb (1) }\end{array}$ & \\
\hline
\end{tabular}

${ }^{a}$ values in parenthesis are expressed in percentage

[26]. In the present study, high sperm DFI did not significantly increase the risk of prematurity or LBW of newborns from patients undergoing ICSI cycles. Bungum et al. reported that sperm DNA damage was not related to birthweight or gestational age of newborns from patients undergoing IVF/ICSI cycles [22]. Sperm DFI did not significantly affect the sex ratio of newborns. The sex ratio of the high sperm DFI group (>30\%) was slightly lower than that of the other groups. This result may be related to the small sample size of the present study. It may also be related to the fact that $\mathrm{Y}$ spermatozoa are more susceptible to stressful conditions than X spermatozoa [27]. High DFI spermatozoa can still fertilize the egg, and subsequent embryo developmental potential and implantation may be impaired, but once a live birth is achieved, neonatal outcomes are not significantly affected.

Sperm DNA damage is often accompanied by numerical and structural chromosomal abnormalities of spermatozoa [28, 29], which can lead to birth defects or congenital malformation in newborns. In the present study, sperm DFI did not significantly affect birth defects of newborns among the three groups. This may be related to the fact that the embryologists would select the spermatozoa with the most normal morphology to inject the oocytes during the ICSI process. This selection was speculated to be related that sperm DFIs from spermatozoa with a normal morphology were significantly lower than those from spermatozoa with an abnormal morphology [17-19]. It was also reported that ICSI performed with spermatozoa selected for better morphology at a high magnification $(>6000 \times)$ can achieve better clinical outcomes than conventional ICSI [30,31]. Some studies found that compared with conventional ICSI, intracytoplasmic morphologically selected sperm injection (IMSI) can decrease the risk of birth defects in newborns [32-34]. On the other hand, this decrease may also be related to the semen processing method. Density gradient centrifugation was used to separate mobile spermatozoa from semen in the present study. Density gradient centrifugation can significantly decrease sperm DFI and the deformity rate $[35,36]$. Rouenet al. reported that discontinuous gradient centrifugation can reduce the percentage of unbalanced spermatozoa in semen from chromosomal rearrangement carriers [37]. A live birth with a balanced karyotype was obtained from sperm selection by discontinuous gradient centrifugation for intrauterine insemination in a patient with a chromosomal translocation [38]. Density gradient centrifugation can also remove ROS (including newly generated ROS) and can prevent separated mobile spermatozoa from oxidative stress [39]. Therefore, density gradient centrifugation can achieve spermatozoa with a better morphology and DNA integrity for assisted reproductive treatment. In addition, the fertilized oocytes or zygotes had a certain ability to repair DNA damage $[40,41]$. These may be the reasons why high DFI did not increase the risk of birth defects in newborns from patients undergoing ICSI cycles.

In the present retrospective study, ejaculated spermatozoa were utilized for conventional ICSI. To obtain better clinical outcomes, Bradley et al. [42] reported that interventions, such as physiological intracytoplasmic sperm injection (PICSI), IMSI and testicular sperm extraction/ aspiration (TESE/TESA), can improve the live-birth rate for patients with high sperm DFI. Among the three interventions, compared with the control spermatozoa, testicular spermatozoa significantly improved the live-birth rate. This may be related to the fact that sperm DFIs from testicular spermatozoa were significantly lower than those of ejaculated spermatozoa [43]. Zhang et al. [44] reported that compared with ejaculated spermatozoa, testicular spermatozoa significantly increased the pregnancy and live-birth rates for patients with high sperm DFIs. Since TESE/TESA is an invasive method, it is generally recommended that testicular spermatozoa are an alternative for patients with high sperm DFI who have failed recurrent ICSI cycles or other less invasive interventions [45]. It has been reported that testicular spermatozoa significantly increase clinical pregnancy and live-birth rates and decrease miscarriages in patients with high sperm DFI who suffer from recurrent ICSI failure [46-48]. Healthy live birth is the most important for patients with high sperm DFI, regardless of testicular spermatozoa or other less invasive interventions.

\section{Conclusions}

Sperm DFI did not compromise the clinical and neonatal outcomes of newborns in our retrospective study. Multicentre and randomized controlled trials are needed to confirm our conclusion. 


\section{Abbreviations}

DFI: DNA fragmentation index; IVF: In vitro fertilization; ICSI: Intracytoplasmic sperm injection; LBW: Low birth weight; ROS: Reactive oxygen species; BMI: Body mass index; IMSI: Intracytoplasmic morphologically selected sperm injection; PICSI: Physiological intracytoplasmic sperm injection; TESE/ TESA: Testicular sperm extraction/aspiration

\section{Acknowledgements \\ Not applicable.}

\section{Authors' contributions}

Linjun Chen formulated the idea for this study and wrote the manuscript Junshun Fang and Weihua Jiang analysed the data. Jie Wang and Dong Li acquired the data. All the authors critically reviewed this article. The authors read and approved the final manuscript.

\section{Funding}

The study was supported by the Nanjing Medical Science and Technology Development Foundation (YKK15070), the Fundamental Research Funds for the Central Universities (021414380135) and the Clinical Medicine Research Special Fund of Chinese Medical Association (17020220691).

\section{Availability of data and materials}

Not applicable.

\section{Ethics approval and consent to participate}

The Ethics Committee of Nanjing Drum Tower Hospital Affiliated with

Nanjing University Medical School approved this study.

\section{Consent for publication}

Not applicable.

\section{Competing interests}

The authors declare that they have no competing interests.

Received: 25 July 2019 Accepted: 27 April 2020

Published online: 02 May 2020

\section{References}

1. Alkhayal A, San Gabriel M, Zeidan K, Alrabeeah K, Noel D, McGraw R, et al. Sperm DNA and chromatin integrity in semen samples used for intrauterine insemination. J Assist Reprod Genet. 2013:30(11):1519-24.

2. Sakkas D, Alvarez JG. Sperm DNA fragmentation: mechanisms of origin, impact on reproductive outcome, and analysis. Fertil Steril. 2010;93(4):1027-36.

3. Santi D, Spaggiari G, Simoni M. Sperm DNA fragmentation index as a promising predictive tool for male infertility diagnosis and treatment management - meta-analyses. Reprod Biomed Online. 2018;37(3):315-26.

4. Alvarez Sedó C, Bilinski M, Lorenzi D, Uriondo H, Noblía F, Longobucco V, et al. Effect of sperm DNA fragmentation on embryo development: clinical and biological aspects. JBRA Assist Reprod. 2017;21(4):343-50.

5. Z Zheng WW, Song G, Wang QL, Liu SW, Zhu XL, Deng SM, et al. Sperm DNA damage has a negative effect on early embryonic development following in vitro fertilization. Asian J Androl. 2018;20(1):75-9.

6. Deng C, Li T, Xie Y, Guo Y, Yang QY, Liang X, et al. Sperm DNA fragmentation index influences assisted reproductive technology outcome: a systematic review and meta-analysis combined with a retrospective cohort study. Andrologia. 2019;51(6):e13263.

7. Zhao J, Zhang Q, Wang Y, Li Y. Whether sperm deoxyribonucleic acid fragmentation has an effect on pregnancy and miscarriage after in vitro fertilization/intracytoplasmic sperm injection: a systematic review and metaanalysis. Fertil Steril. 2014;102(4):998-1005.e8.

8. Sun TC, Zhang Y, Li HT, Liu XM, Yi DX, Tian L, et al. Sperm DNA fragmentation index, as measured by sperm chromatin dispersion, might not predict assisted reproductive outcome. Taiwan J Obstet Gynecol. 2018 57(4):493-8.

9. Gat I, Tang K, Quach K, Kuznyetsov V, Antes R, Filice M, et al. Sperm DNA fragmentation index does not correlate with blastocyst aneuploidy or morphological grading. PLoS One. 2017;12(6):e0179002.
10. Zhang $Z$, Zhu L, Jiang $H$, Chen $H$, Chen $Y$, Dai $Y$. Sperm DNA fragmentation index and pregnancy outcome after IVF or ICSI: a meta-analysis. J Assist Reprod Genet. 2015;32(1):17-26.

11. Cissen M, Wely MV, Scholten I, Mansell S, Bruin JP, Mol BW, et al. Measuring sperm DNA fragmentation and clinical outcomes of medically assisted reproduction: a systematic review and meta-analysis. PLoS One. 2016;11(11): e0165125.

12. Antonouli S, Papatheodorou A, Panagiotidis Y, Petousis S, Prapas N, Nottola SA, et al. The impact of sperm DNA fragmentation on ICSI outcome in cases of donated oocytes. Arch Gynecol Obstet. 2019;300(1):207-15.

13. Zegers-Hochschild F, Adamson GD, Dyer S, Racowsky C, de Mouzon J, Sokol $\mathrm{R}$, et al. The international glossary on infertility and fertility care, 2017. Hum Reprod. 2017:32(9):1786-801.

14. Yang $H, L i ~ G$, Jin H, Guo $Y$, Sun $Y$. The effect of sperm DNA fragmentation index on assisted reproductive technology outcomes and its relationship with semen parameters and lifestyle. Transl Androl Urol. 2019;8(4):356-65.

15. Green KA, Patounakis G, Dougherty MP, Werner MD, Scott RT Jr, Franasiak JM. Sperm DNA fragmentation on the day of fertilization is not associated with embryologic or clinical outcomes after IVF/ICSI. J Assist Reprod Genet. 2020;37(1):71-6

16. Zhu XB, Chen Q, Fan WM, Niu ZH, Xu BF, Zhang AJ. Sperm DNA fragmentation in Chinese couples with unexplained recurrent pregnancy oss. Asian J Androl. 2019;21:1-6.

17. Sivanarayana T, Krishna CR, Prakash GJ, Krishna KM, Madan K, Rani BS, et al. CASA derived human sperm abnormalities: correlation with chromatin packing and DNA fragmentation. J Assist Reprod Genet. 2012;29(12):1327-34.

18. Daris B, Goropevsek A, Hojnik N, Vlaisavljević V. Sperm morphological abnormalities as indicators of DNA fragmentation and fertilization in ICSI. Arch Gynecol Obstet. 2010;281(2):363-7.

19. Mangiarini A, Paffoni A, Restelli L, Ferrari S, Guarneri C, Ragni G, et al. Specific sperm defects are differentially correlated with DNA fragmentation in both normozoospermic and teratozoospermic subjects. Andrology. 2013;1(6):838-44.

20. Simon L, Proutski I, Stevenson M, Jennings D, McManus J, Lutton D, et al. Sperm DNA damage has a negative association with live-birth rates after IVF. Reprod Biomed Online. 2013;26(1):68-78.

21. Osman A, Alsomait H, Seshadri S, El-Toukhy T, Khalaf Y. The effect of sperm DNA fragmentation on live birth rate after IVF or ICSI: a systematic review and meta-analysis. Reprod Biomed Online. 2015;30(2):120-7.

22. Bungum M, Bungum L, Lynch KF, Wedlund L, Humaidan P, Giwercman A. Spermatozoa DNA damage measured by sperm chromatin structure assay (SCSA) and birth characteristics in children conceived by IVF and ICSI. Int J Androl. 2012;35(4):485-90.

23. Esteves SC, Agarwal A, Majzoub A. Live birth must be the primary reproductive endpoint in IVF/ICSI studies evaluating sperm DNA fragmentation testing. Transl Androl Urol. 2017;6(Suppl 4):S564-5.

24. Cavoretto P, Candiani M, Giorgione V, Inversetti A, Abu-Saba MM, Tiberio F, et al. Risk of spontaneous preterm birth in singleton pregnancies conceived after IVF/ICSI treatment: meta-analysis of cohort studies. Ultrasound Obstet Gynecol. 2018:51(1):43-53.

25. Qin JB, Sheng XQ, Wu D, Gao SY, You YP, Yang TB, et al. Worldwide prevalence of adverse pregnancy outcomes among singleton pregnancies after in vitro fertilization/intracytoplasmic sperm injection: a systematic review and meta-analysis. Arch Gynecol Obstet. 2017:295(2):285-301.

26. Seggers J, Pontesilli M, Ravelli ACJ, Painter RC, Hadders-Algra M, Heineman $\mathrm{MJ}$, et al. Effects of in vitro fertilization and maternal characteristics on perinatal outcomes: a population-based study using siblings. Fertil Steril. 2016;105(3):590-8.e2.

27. You YA, Kwon WS, Saidur Rahman M, Park YJ, Kim YJ, Pang MG. Sex chromosome-dependent differential viability of human spermatozoa during prolonged incubation. Hum Reprod. 2017;32(6):1183-91.

28. Enciso M, Alfarawati S, Wells D. Increased numbers of DNA-damaged spermatozoa in samples presenting an elevated rate of numerical chromosome abnormalities. Hum Reprod. 2013;28(6):1707-15.

29. Perrin A, Nguyen MH, Bujan L, Vialard F, Amice $V$, Guéganic N, et al. DNA fragmentation is higher in spermatozoa with chromosomally unbalanced content in men with a structural chromosomal rearrangement. Andrology. 2013;1(4):632-8

30. Setti AS, Braga DP, Figueira RC, laconelli A Jr, Borges E. Intracytoplasmic morphologically selected sperm injection results in improved clinical outcomes in couples with previous ICSI failures or male factor infertility: a meta-analysis. Eur J Obstet Gynecol Reprod Biol. 2014;183:96-103. 
31. Lo Monte G, Murisier F, Piva I, Germond M, Marci R. Focus on intracytoplasmic morphologically selected sperm injection (IMSI): a minireview. Asian J Androl. 2013;15(5):608-15.

32. Hershko-Klement A, Sukenik-Halevy R, Biron Shental T, Miller N, Berkovitz A. Intracytoplasmic morphologically selected sperm injection and congenital birth defects: a retrospective cohort study. Andrology. 2016;4(5):887-93.

33. Gaspard O, Vanderzwalmen P, Wirleitner B, Ravet S, Wenders F, Eichel V, et al. Impact of high magnification sperm selection on neonatal outcomes: a retrospective study. J Assist Reprod Genet. 2018;35(6):1113-21.

34. Cassuto NG, Hazout A, Bouret D, Balet R, Larue L, Benifla JL, et al. Low birth defects by deselecting abnormal spermatozoa before ICSI. Reprod Biomed Online. 2014;28(1):47-53.

35. Xue X, Wang WS, Shi JZ, Zhang SL, Zhao WQ, Shi WH, et al. Efficacy of swim-up versus density gradient centrifugation in improving sperm deformity rate and DNA fragmentation index in semen samples from teratozoospermic patients. J Assist Reprod Genet. 2014;31(9):1161-6.

36. Wang M, Sun J, Wang L, Gao X, Lu X, Wu Z, et al. Assessment of density gradient centrifugation (DGC) and sperm chromatin dispersion (SCD) measurements in couples with male factor infertility undergoing ICSI. J Assist Reprod Genet. 2014;31(12):1655-63.

37. Rouen A, Balet R, Dorna M, Hyon C, Pollet-Villard X, Chantot-Bastaraud S, et al. Discontinuous gradient centrifugation (DGC) decreases the proportion of chromosomally unbalanced spermatozoa in chromosomal rearrangement carriers. Hum Reprod. 2013;28(7):2003-9.

38. Rouen A, Hyon C, Balet R, Joyé N, Cassuto NG, Siffroi JP. First birth after sperm selection through discontinuous gradient centrifugation and artificial insemination from a chromosomal translocation carrier. Case Rep Genet. 2014;2014:906145.

39. Takeshima T, Yumura Y, Kuroda S, Kawahara T, Uemura H, Iwasaki A. Effect of density gradient centrifugation on reactive oxygen species in human semen. Syst Biol Reprod Med. 2017;63(3):192-8.

40. Ménézo Y, Dale B, Cohen M. DNA damage and repair in human oocytes and embryos: a review. Zygote. 2010;18(4):357-65.

41. Martin JH, Aitken RJ, Bromfield EG, Nixon B. DNA damage and repair in the female germline: contributions to ART. Hum Reprod Update. 2019;25(2): 180-201.

42. Bradley CK, McArthur SJ, Gee AJ, Weiss KA, Schmidt U, Toogood L. Intervention improves assisted conception intracytoplasmic sperm injection outcomes for patients with high levels of sperm DNA fragmentation: a retrospective analysis. Andrology. 2016;4(5):903-10.

43. Esteves SC, Roque M, Bradley CK, Garrido N. Reproductive outcomes of testicular versus ejaculated sperm for intracytoplasmic sperm injection among men with high levels of DNA fragmentation in semen: systematic review and meta-analysis. Fertil Steril. 2017;108(3):456-67.e1.

44. Zhang J, Xue H, Qiu F, Zhong J, Su J. Testicular spermatozoon is superior to ejaculated spermatozoon for intracytoplasmic sperm injection to achieve pregnancy in infertile males with high sperm DNA damage. Andrologia. 2019;51(2):e13175

45. Esteves SC, Majzoub A, Agarwal A. More good than harm should be expected when Testi-ICSI is applied to oligozoospermic men with posttesticular sperm DNA fragmentation. Transl Androl Urol. 2017;6(Suppl 4): S381-4.

46. Lopes LS, Esteves SC. Testicular sperm for intracytoplasmic sperm injection in non-azoospermic men: a paradigm shift. Panminerva Med. 2019;61(2): 178-86.

47. Pabuccu EG, Caglar GS, Tangal S, Haliloglu AH, Pabuccu R. Testicular versus ejaculated spermatozoa in ICSI cycles of normozoospermic men with high sperm DNA fragmentation and previous ART failures. Andrologia. 2017;49(2):1-7.

48. Herrero MB, Lusignan MF, Son WY, Sabbah M, Buckett W, Chan P. ICSI outcomes using testicular spermatozoa in non-azoospermic couples with recurrent ICSI failure and no previous live births. Andrology. 2019;7(3):281-7.

\section{Publisher's Note}

Springer Nature remains neutral with regard to jurisdictional claims in published maps and institutional affiliations.

\section{Ready to submit your research? Choose BMC and benefit from:}

- fast, convenient online submission

- thorough peer review by experienced researchers in your field

- rapid publication on acceptance

- support for research data, including large and complex data types

- gold Open Access which fosters wider collaboration and increased citations

- maximum visibility for your research: over $100 \mathrm{M}$ website views per year

At BMC, research is always in progress.

Learn more biomedcentral.com/submissions 